Contract No. and Disclaimer:

This manuscript has been authored by Savannah River Nuclear Solutions, LLC under Contract No. DE-AC09-08SR22470 with the U.S. Department of Energy. The United States Government retains and the publisher, by accepting this article for publication, acknowledges that the United States Government retains a non-exclusive, paid-up, irrevocable, worldwide license to publish or reproduce the published form of this work, or allow others to do so, for United States Government purposes. 


\section{Evaluation of active cap materials for metal retention in sediments}

Anna. S. Knox ${ }^{1 *}$, Michael H. Paller ${ }^{1}$, and Kenneth L. Dixon ${ }^{1}$

${ }^{1}$ Savannah River National Laboratory, Savannah River Site, 773-42A, Aiken, SC, 29808

* Corresponding author: anna.knox@srnl.doe.gov, 803-725-7021 voice, 803-725-7673 fax

This study evaluated chemically active amendments used to construct active caps for remediating contaminated sediments. Three experiments assessed the effects of apatite, organoclay, zeolite, and biopolymers (chitosan and xanthan) on metal mobility, retention, and speciation. The first showed that the amendments individually and in mixtures ( $2 \%$ dry weight) reduced the concentrations of $\mathrm{Cr}, \mathrm{Co}, \mathrm{Ni}$, and $\mathrm{Pb}$ in water extracts from reduced sediment. The second experiment, which used sequential extraction procedures to evaluate the effects of the amendments on metal speciation, showed that the amendments reduced the potentially mobile fractions of $\mathrm{Pb}, \mathrm{Zn}, \mathrm{Ni}, \mathrm{Cr}$, and $\mathrm{Cd}$ that are likely to be bioavailable. Last, column studies showed that active caps composed of the amendments prevented the diffusive transport of metals from contaminated sediment over six months. In addition, there was a "zone of influence" beneath the caps in which water extractable concentrations of metals declined substantially compared with untreated sediment.

Key Words: Apatite, organoclay, biopolymers, zeolite, contaminated sediment, active caps 


\section{INTRODUCTION}

Water is a highly precious resource. More than half of the world's animal and plant species live in the water. Less than $5 \%$ is nonsaline, while only $0.2 \%$ and $0.3 \%$ are found in lake and rivers, respectively, and readily available for human use (Yong, 2001). Therefore, protection of water and sediment quality is highly important. Rapid industrialization and urbanization leads to the contamination of sediments with heavy metals and organic contaminants and creates a pervasive problem worldwide. Major sources of metal pollutants for the aquatic environment include agricultural and urban lands, industrial activities, spills, and accidents. In general, such pollutants enter the environment through surface runoff that discharges into rivers, lakes, and groundwater or through point sources from municipalities, industries, or other sources. These contaminants pose a potential risk to the environment and human health because they can harm aquatic organisms and enter aquatic food chains that lead to humans. Metals that enter the aquatic environment often accumulate in sediments that subsequently act as a source for contaminant remobilization. Metals, including $\mathrm{As}, \mathrm{Cd}, \mathrm{Cu}, \mathrm{Hg}, \mathrm{Ni}$, and $\mathrm{Pb}$ are often found in harbor sediments and other areas affected by anthropogenic activities.

The traditional method for managing contaminated sediments is dredging. However, this method is relatively expensive and can mobilize contaminants and destroy benthic ecosystems. Dredged sediments, which often contain significant levels of contaminants, are either landfilled or ocean disposed where they can cause further problems. The limitations of dredging have led to consideration of other technologies including the application of chemically reactive amendments that change the chemical speciation of sediment contaminants to reduce their mobility/bioavailability and increase their retention in sediments. Control of metal speciation is important because only the contaminant fraction that is available for biological uptake has the 
potential to cause human health or ecological risks. Chemically reactive amendments are used to construct active caps, which usually consist of a relatively thin layer of a reactive amendment or a mixture of amendments sometimes combined with inert materials (Knox et al., 2011). Active caps have advantages over passive caps composed solely of inert materials because they can minimize potential risks resulting from contaminant migration through the cap and can be applied in areas where thick passive caps are impractical or undesirable. In addition, the reactive materials used in active caps are able to immobilize contaminants in sediments beneath the caps (i.e., in the zone-of-influence) in addition to preventing contaminant migration into the water column (Knox et al., 2011).

The selection of appropriate amendments for sediment remediation requires a clear understanding of the factors affecting contaminant mobility and bioavailability in the sediments. The effectiveness of active amendments on the sequestration of metals is based on several factors including metal concentrations, $\mathrm{pH}$, redox potential, and other competing ions and anions. Burrowing organisms that bioturbate and bioirrigate the sediments can also influence metal speciation and fluxes. The dynamic equilibrium between oxidized and reduced forms of iron, manganese, and sulfur play a crucial role in controlling metal speciation and fluxes in aquatic environments (Simpson et al., 2002). These elements often coexist in nonequilibrium conditions, with small disturbances in sediment microenvironments having the potential to produce rapid changes in metal oxidation states and partitioning. High-resolution studies of the sediment-water interface indicate sharp concentration maxima for many trace metals in the top 1.5-3.0 mm of sediment that may drive metal fluxes into overlying waters (Zhang et al., 1995). Metal concentrations at this depth are often strongly affected by iron/manganese redox chemistry 
because this zone coincides with the depth at which iron and manganese hydroxides are reductively solubilized.

There are currently a variety of sequestering agents for use in active caps including phosphates, organoclay, activated charcoal, zeolites, and biopolymers. Properly selected phosphate amendments mixed in contaminated sediment or soils can reduce metal mobility, bioavailability, and toxicity (Knox et al., 2006 a). Apatite, for example, is a readily available phosphate source that can immobilize $\mathrm{Pb}$ and other metals (e.g., $\mathrm{Cd}, \mathrm{Ni}, \mathrm{Zn}$, and $\mathrm{U}$ ) in surface and subsurface soils/sediments, thereby offering an economical, simple, and environmentally benign treatment for contaminated environments (Knox et al., 2006 a, and 2011).

Organoclays consist of bentonite that is modified with quaternary amines. Bentonite becomes organically modified by exchanging the nitrogen end of a quaternary amine onto the surface of the clay platelets through cation exchange (Lagaly 1984). Organoclays are particularly effective at removing non-polar pollutants such as oil, polychlorinated biphenols, chlorinated solvents, and polycyclic aromatic hydrocarbons (Xu et al., 1997; Alther 2002). Organoclays have been used as liners in landfills to diminish the transport of pollutants into water supplies (Xu et al., 1997) and in waste water treatment (Soundarajan et al., 1990).

Zeolites are crystalline aluminosilicate minerals consisting of three-dimensional networks of linked $\mathrm{SiO}_{4}$ and $\mathrm{AlO}_{4}$ tetrahedra. They are porous, with channels up to 0.8-1.0 nm in diameter that lead into large framework cavities or cages, allowing for selective entry of cations and molecules. The geometry and chemistry of each zeolite mineral is unique, giving rise to a variety of sorption properties that are selective for specific molecules or cations. The unique physical and chemical properties of zeolites combined with their natural abundance have resulted in their widespread use in numerous agricultural and industrial processes. The use of zeolites for 
pollution control is dependent on their ion-exchange properties. Clinoptilolite and phillipsite, both natural zeolites, are commonly used for the remediation of contaminated soils and sediments.

Biopolymers are high-molecular weight compounds with repeated sequences that may become multiple reactive sites for chemical interaction with other compounds. The ability of biopolymers (cross-linked or not) to bind a large variety of metals (including $\mathrm{Cu}, \mathrm{Pb}, \mathrm{Cd}, \mathrm{As}, \mathrm{Cr}$, Hg, Zn, Ni, Au) is supported by many studies (Schmuhl et al., 2001; Vankar and Tiwari, 2001). This paper presents an evaluation of low-cost, commercially available, chemically active amendments (phosphates, organoclays, zeolites, and biopolymers) that can be used in active caps for the remediation of sediments contaminated with metals. The effectiveness of the amendments for use in active caps is based on their effects on metal speciation, mobility, and metal retention in sediments. To assess these properties, we first evaluated the relative abilities of the amendments to immobilize metals in samples of contaminated sediment held under both oxidized and reduced conditions because the dynamic equilibrium between oxidized and reduced forms of iron, manganese, and sulfur can play a crucial role in controlling metal speciation and fluxes in aquatic environments. We then used sequential extraction procedures to evaluate the effects of the amendments on metal speciation, thereby providing a greater understanding of the mechanisms of metal immobilization by the amendments. Last, we conducted a bench-scale evaluation of the ability of active caps composed of various amendments and amendment combinations to control the diffusive transport of metals from contaminated sediment into the water column. This included an evaluation of the zone of influence, i.e., effect of amendments on the sediment beneath the applied materials. 


\section{MATERIALS AND METHODS}

\section{Effects of Amendments on Metal Mobility under Oxidized and Reduced Conditions}

Rock phosphate from North Carolina (NCA); organoclay from Biomin Inc. (OCB); the natural zeolite, clinoptilolite (ZC); and sand coated with the biopolymer xanthan cross-linked with chitosan and calcium chloride (XCc) were evaluated to determine their effects on metal mobility. Sand was coated with biopolymer to facilitate the delivery of biopolymer to the sediment surface under field conditions (described more fully in Knox et al., 2011). The amendments were evaluated individually and in mixtures of two or three amendments. The amendments and amendment mixtures were tested under both reduced and oxidized conditions. Sediments, contaminated with metals and organics compounds, were collected from the Anacostia River near Washington DC. For reduced conditions, $40 \mathrm{~g}$ of Anacostia River sediment, $2 \mathrm{~g}$ of amendment or amendment mixture ( $5 \%$ by weight), and $25-\mathrm{mL}$ of pore water from the Anacostia River sediment was added to 50-mL tubes, which were filled to the top (to eliminate any air space) and sealed. The tubes were then placed on a platform shaker in the dark for eight weeks before separating the solids and liquids for chemical characterization.

Disposable filtration units were used for the oxidized treatments. These $115 \mathrm{~mL}$ plexiglass containers consisted of two chambers separated by a $0.45 \mu \mathrm{m}$ filter membrane. Forty g of the Anacostia River sediment, $2 \mathrm{~g}$ of amendment or amendment mixture, and $25 \mathrm{~mL}$ of pore water from the Anacostia River sediment were added to the treated sediment. The units were left open to provide oxygen exchange with the atmosphere. After eight weeks, the remaining water in each unit was suction vacuumed through the filter. Untreated sediment was used as a control in both the oxidized and reduced treatments. 
Water collected from both treatments was measured for $\mathrm{pH}$, Eh (a measure of the redox status), dissolved $\mathrm{O}_{2}$, dissolved organic carbon (DOC), and electrical conductivity (EC, a measure of the total concentration of ions in solution). Metals were analyzed by ICP-MS. The resulting concentrations reflected the water extractable pool of metals under reduced and oxidizing conditions.

\section{Effects of Amendments on Metal Speciation}

A sequential extraction scheme based on modified methods of Tessier et al. (1979) was used to evaluate the distribution of metals in untreated and treated sediment. The following fractions were extracted: 1) exchangeable, 2) carbonate, 3) amorphous Fe and Mn oxides, 4) crystalline Fe and Mn oxides, 5) organic, 6) sulfides, and 7) residual (Exhibit 1).

Contaminated sediment collected from the Elizabeth River near Portsmouth Virginia was used for this experiment. The sediment was amended with NCA at three rates (2.5\%, $5 \%$, and $10 \%$ of the sediment wet weight), with OCB at $2.5 \%$ wet weight, and with a mixture of $50 \%$ NCA and 50\% OCB (2.5\% wet weight). Sequential extractions were performed on the treated sediments and on untreated sediments, which served as a control. All extractions, except the final digestion, were conducted in $50 \mathrm{~mL}$ polypropylene centrifuge vials to minimize losses of solid material. Separation of extracts from sediments was achieved by centrifuging at $2400 \mathrm{rpm}$ for 20 min between each successive extraction. The supernatant was removed with a pipette, filtered through a $0.45 \mu \mathrm{m}$ filter, and stored for analysis. The residue was washed with $10 \mathrm{~mL}$ of nanopure water (resistivity greater than $18.0 \mathrm{M} \Omega \mathrm{cm}$, conductivity less than $0.055 \mu \mathrm{sm}^{-1}$ ), centrifuged, and the supernatant was added to the sample extract. The nanopure water was obtained from a water purification system EASY II LF (model D738, Barnstead International, Dubuque, IA). The residual and total concentrations of elements were determined by a total 
microwave digestion of $1 \mathrm{~g}$ of sediment with aqua regia (mixture of concentrated $\mathrm{HCl}$ and $\mathrm{HNO}_{3}$ at ratio 3:1). The extracted solutions from all fractions were analyzed by inductively coupled plasma mass spectrometry (ICP-MS).

\section{Evaluation of Diffusive Transport through Active Caps}

\section{Diffusion of metals through active caps}

The sediment used in this experiment was from Tims Branch, a stream located near Aiken, SC. It was spiked with $8 \mathrm{mg} \mathrm{L}^{-1}$ of $\mathrm{Cd}, \mathrm{Cr}, \mathrm{Co}, \mathrm{As}, \mathrm{Ni}, \mathrm{Se}, \mathrm{Zn}$, and $\mathrm{Pb}$ and permitted to equilibrate for two weeks. A $10 \mathrm{~cm}$ layer (421 grams) of spiked sediment was placed at the bottom of each of ten $5 \mathrm{~cm}$ diameter clear plastic tubes. Four types of simulated caps (each $5 \mathrm{~cm}$ thick) were placed on the top of the sediment: single layer caps composed of NCA; single layer caps composed of OCB; two layer caps composed of XCc and NCA; and three layer caps composed of XCc, NCA, and OCB. Each layer was $2.5 \mathrm{~cm}$ thick in the two layer caps and $1.7 \mathrm{~cm}$ thick in the three layer caps. Untreated sediment and sand caps served as a control. Each type of cap was replicated twice. The simulated caps and underlying sediment were saturated with DI water, after which $500 \mathrm{ml}$ of DI water was added to each tube.

Water samples were collected two days, one month, two months, four months, and six months after the start of the study. The samples were collected from the center of the water column (about $10 \mathrm{~cm}$ from the surface), and one sample was collected from each tube. All water samples were analyzed for $\mathrm{pH}$, EC, and metals by ICP-MS. The four and six month samples were analyzed for total carbon (TC), total inorganic carbon (TIC), and total organic carbon (TOC). Differences in metal concentrations among treatments were evaluated with a two-way repeated measures analysis of variance (ANOVA) in which consecutive samples from each column were the repeated measure and treatment was the experimental factor. A separate 
ANOVA was conducted for each metal, and differences were considered significant at $\mathrm{P} \leq 0.05$.

The metal data were $\log _{10}$ transformed prior to analysis to better meet the ANOVA assumptions of normality and homogeneity of variance.

TC and TIC were measured with an OI Analytical Combustion TOC Analyzer, model 1020A. The sample was first transferred to a vessel that would not contribute TC and then introduced to the TOC Analyzer through a sipper, which pulled a fixed volume for analysis. The aqueous sample was heated to approximately $900^{\circ} \mathrm{C}$ in a high oxygen environment, and the TC evolved as $\mathrm{CO}_{2}$ was measured. TIC was determined by adding phosphoric acid to the sample and measuring the gas devolved. TOC was calculated from the difference in the TC and TIC measurements.

\section{Zone of influence (ZOI) of active caps}

The diffusion experiment was terminated after six months, and the water was decanted and analyzed for $\mathrm{pH}, \mathrm{EC}, \mathrm{TC}$, TIC, TOC, and metals. The solids were separated into cap material and sediment. The sediment was sliced into four layers: A $(0-1.5 \mathrm{~cm}), \mathrm{B}(1.5-2.5 \mathrm{~cm}), \mathrm{C}(2.5$ - 5 $\mathrm{cm})$, and D (5-10 cm). Two grams of sediment from each layer were extracted with $10 \mathrm{ml}$ of DI water and analyzed for metal concentrations by ICP-MS. The results were used for evaluation of the ZOI created by the diffusion of active cap materials into the sediment beneath the active caps.

A Solids TOC Analyzer manufactured by OI Analytical was used to measure both TC and TOC in the sediment samples. Approximately $0.5 \mathrm{~g}$ of sample was added to a sample cup, which was exposed to a temperature and time regime appropriate for the parameter being measured in the TOC analyzer. TC was determined by measuring the quantity of carbon dioxide $\left(\mathrm{CO}_{2}\right)$ devolved when the sample was heated to approximately $900^{\circ} \mathrm{C}$ in an oxygen atmosphere, 
which removed all carbon present as $\mathrm{CO}_{2}$ gas. TOC measurements required acidification with hydrochloric acid followed by heating at $250^{\circ} \mathrm{C}$ in an oxygen atmosphere to purge the sample of TIC. The sample was then heated to $950^{\circ} \mathrm{C}$, and the quantity of $\mathrm{CO}_{2}$ released was measured, which came only from TOC. TIC was determined by subtracting TOC from TC.

\section{RESULTS AND DISCUSSION}

\section{Effects of Amendments on Metal Mobility under Oxidized and Reduced Conditions}

The chemistry of water extracts from the oxidized and reduced treatments differed significantly (Exhibit 2). The redox potential was about $-200 \mathrm{mV}$ in the reduced treatments and about $-15 \mathrm{mV}$ in the oxidized treatments. Dissolved oxygen concentrations were about $1 \mathrm{mg} \mathrm{L}^{-1}$ or less in the reduced treatments and about $7 \mathrm{mg} \mathrm{L}^{-1}$ in the oxidized treatments. Differences in $\mathrm{pH}$ and EC between treatments were smaller but still substantial (Exhibit 2). Generally, the addition of apatite and biopolymer to Anacostia River sediment did not significantly influence EC values, especially in reduced treatments. However, addition of zeolite and organoclay significantly increased EC values in both oxidized and reduced treatments (Exhibit 2).

The addition of 2\% (dry weight) of apatite, zeolite, biopolymer, and organoclay, by themselves or as part of a mixture influenced the concentrations of elements in water extracts from both reduced and oxidized treatments. Generally, all amendments reduced Fe and Mn concentrations under reduced conditions (Exhibit 3). However, the addition of North Carolina apatite increased P concentration from 2.5 to $3.3 \mathrm{mg} \mathrm{L}^{-1}$ and from 0.8 to $1.4 \mathrm{mg} \mathrm{L}^{-1}$; under reduced and oxidized conditions, respectively. Addition of NCA increased the Ca concentration under oxidized conditions (Exhibit 3). Addition of other amendments generally reduced Ca concentration under oxidized condition. 
The concentrations of most metals in water extracts from the sediments were lower than is typical of contaminated sediments and often below drinking water standards (Exhibit 4). In the oxidized treatments, element concentrations were very low and often near the detection limit for ICP-MS. However, water extractable metal concentrations were generally higher under reduced conditions (Exhibit 4).

NCA, a mixture of NCA with chitosan and zeolite, and a mixture of NCA with OCB substantially reduced water extractable $\mathrm{Cr}, \mathrm{Co}, \mathrm{Ni}$, and $\mathrm{Pb}$ concentrations in the reduced sediments (Exhibit 5). Other elements such as As, Cd, and Se showed some reduction (e.g., in case of NCA); however, effects were not consistent for all amendments. The addition of 2\% zeolite or a mixture of NCA with biopolymer, zeolite, or OCB reduced Cd concentrations in the water extracts from the oxidized treatments (Exhibit 6). Lead concentrations were significantly reduced by all individual amendments and amendment mixtures under oxidized conditions (Exhibit 6).

\section{Effects of Amendments on Metal Speciation}

The total concentration of a sedimentary metal can have little relevance to its bioavailability. The bioavailability of different metals in contaminated sediments is likely to be a function of a metal's characteristics - for example charge, ionic radius, and oxidation state, its chemical form and phase speciation in the sediment (Lee et al., 2000; Griscom at al., 2000). Addition of amendments to sediments results in changes of sediment chemistry; e.g., amendments will change sediment $\mathrm{pH}$, redox (in case of a cap) and chemical phases of elements and minerals. Sequential extraction can help to evaluate these changes. Several studies show that metals bound to more refractory fractions are less available for organisms than metals loosely bound to sediment particle surfaces in exchangeable and carbonate fractions (Griscom et al., 2000). 


\section{Sequential extraction of cadmium (Cd) in sediment treated with active cap amendments}

In soils and sediments, Cd may be adsorbed by clay minerals (e.g., illite), carbonates, or hydrous oxides of iron and manganese, or it may be precipitated as Cd carbonate, hydroxide, or phosphate phase. Dudley et al. (1991) suggested that adsorption mechanisms may be dominant for the deposition of $\mathrm{Cd}$ in soil and sediment. Apatite is known to effectively remove soluble Cd (Wright 1995). From results for short-term contact studies with the use of fossil apatite mineral, Ma et al. (1997) concluded that minor octavite $\left(\mathrm{CdCO}_{3}\right)$ precipitation does occur, but that sorption mechanisms (such as surface complexation, ion exchange, or the formation of amorphous solids) are primarily responsible for the removal of soluble Cd. Cadmium phosphate, if formed, should be more stable than otavite under acidic conditions (Chen et al., 1997).

The partitioning of Cd within the various fractions of the untreated and treated Elizabeth River sediment is illustrated in Exhibit 7. The distribution patterns are similar for the sediment with and without amendments, except that the proportion of Cd in exchangeable, carbonate, and amorphous oxides was substantially greater in the untreated sediments (Exhibit 7). The greatest increase in the Cd sulfide fraction was observed for the addition of $10 \%$ NCA. The residual fraction increased proportionally to the increased dose of NCA, with the highest values for the 10\% addition of NCA (Exhibit 7). Similar patterns of Cd distribution among the fractions were observed for the addition of OCB and the mixture of OCB and NCA (Exhibit 7).

\section{Sequential extraction of lead $(\mathrm{Pb})$ in sediment treated with active cap amendments}

Most Pb salts (e.g., phosphates, sulfates, sulfides, carbonates, hydroxides) are either sparingly soluble or almost completely insoluble. Lead interacts strongly with clay minerals, oxides of Fe and Mn, and with organic matter such as humic acids (McLean and Bledsoe, 1992). As a result, $\mathrm{Pb}$ solubility and mobility is low in most subsurface systems. In natural waters at $\mathrm{pH}>7, \mathrm{~Pb}$ is 
either adsorbed on clay surfaces or forms Pb-carbonate precipitate. Lead has a strong affinity for organic ligands, and the formation of such complexes may greatly increase $\mathrm{Pb}$ mobility in sediments. The long-term stability of Pb-compounds in sediments depends upon differences in the nearly insoluble phases; e.g., pyromorphite-type phosphate minerals versus carbonate or hydroxide phases. Lead phosphates, especially pyromorphite minerals, demonstrate minimal solubility and bioassessibility (Ruby, 1996).

For the untreated Elizabeth sediment, the $\mathrm{Pb}$ was predominantly associated with the amorphous Fe and Me oxide fraction, presumably by sorption to these oxides (Exhibit 7). The next most abundant fractions were the residual and sulfite fractions, with the exchangeable fraction being the least abundant (Exhibit 7). As expected, the additions of NCA (2.5\%, 5.0\%, and $10 \%$ by weight) shifted $\mathrm{Pb}$ from amorphous oxide, carbonate, and exchangeable fractions, to the sulfide and residual fractions. The largest shift was observed with the addition of $10 \%$ NCA (Exhibit 7).

\section{Sequential extraction of zinc (Zn) in sediment treated with active cap amendments}

Zinc may be sequestered by reaction with apatite, as demonstrated by Wright et al., (1995). Chen et al. (1997) reported that sorptive removal of $\mathrm{Zn}(\mathrm{II})$ by apatite is $\mathrm{pH}$ dependent, with a sharp increase in the removal of soluble $\mathrm{Zn}$ when the final solution $\mathrm{pH}$ value is >6.5. Chen et al. (1997) also reported that hopeite $\left[\mathrm{Zn}_{3}\left(\mathrm{PO}_{4}\right)_{2} 4 \mathrm{H}_{2} \mathrm{O}\right]$ is the principal mineral phase formed by interaction of $\mathrm{Zn}(\mathrm{II})$ and apatite at near-neutral $\mathrm{pH}$ values.

For untreated sediment, Zn was predominantly associated with the amorphous oxide and carbonate fractions, which are relatively mobile (Exhibit 7). Oxyhydroxide (oxide) minerals, along with organic matter, have been recognized as the predominant metal sorbents in aquatic systems. The addition of only 2.5\% (by dry weight) of NCA or OCB reduced the exchangeable 
pool of zinc by $90 \%$. Also, carbonate and amorphous oxide fractions were substantially reduced in the Elizabeth River sediment when treated with NCA or OCB (Exhibit 7). The reduction of relatively mobile fractions such as the exchangeable, carbonate, and amorphous resulted in new mineral phases associated with the crystalline, sulfide, and residual fractions (Exhibit 7).

\section{Potentially mobile and recalcitrant fractions in sediment treated with amendments}

Sequential extraction results can be summarized using the concepts of the Potentially Mobile Fraction (PMF) and Recalcitrant Factor (RF) (Knox et al., 2006 b). Early extraction steps (exchangeable, carbonate, amorphous oxides, and organic fractions) tend to recover metal fractions that are less strongly bound than the fractions collected in the later extraction steps (crystalline oxides, sulfides, and residue fractions). The less strongly bound fractions can be termed the PMF because they constitute the contaminant fraction that has the potential to enter into the mobile aqueous phase in response to changing environmental conditions, such as $\mathrm{pH}$, Eh, temperature, etc. The PMF for the untreated and treated Elizabeth River sediment was calculated using the equation shown below:

$$
\text { Potentially Mobile Fraction }=100-\left(F_{\text {Cry. oxides }}+F_{\text {Sulfide }}+F_{\text {Residual }}\right)
$$

where $\mathrm{F}$ Cry. oxides represents the crystalline Fe oxide fraction (wt-\%), $\mathrm{F}_{\text {Sulfide }}$ the sulfide fraction (wt-\%), and $\mathrm{F}_{\text {Residual }}$ the residual fraction (wt-\%).

Fractions of the contaminant pool that are very strongly bound by the sediment include crystalline oxides, sulfides or silicates, and aluminosilicates. These strongly bound fractions were used to calculate the RF. The RF is the ratio of strongly bound fractions to the total concentration of the element (i.e., sum of all fractions) in the sediment. The RF indicates the virtually irreversible retention of metals by the solid phase. 
The RF was calculated using the equation shown below:

$$
\text { Recalcitrant Factor }=\left[\frac{\text { Ccry.oxides }+ \text { Cs }+ \text { Cresidual }}{\text { Cexch }+ \text { Cc }+ \text { Corg }+ \text { Coxides }+ \text { Cs }+ \text { Cresidual }}\right] \times 100
$$

where $C$ represents concentration, and the subscripts crystalline oxides (cry. oxides), sulfides (s) and residual, represent the three final fractions of the sequential extractions. The subscripts exch, c, org, and oxides stand for water soluble and exchangeable metals, carbonates, organically bound metals, and metals bound to amorphous and crystalline oxides, respectively. This construct provides an estimate of the percentage of a contaminant in the sediment that is resistant to remobilization; i.e., retention of contaminants in sediments.

Of the seven tested elements, Cd, Zn, Co, and Pb showed the highest PMF values in the untreated sediment - more than 50\% (Exhibit 8). Addition of amendments such as apatite or organoclay to the sediment reduced the PMF values of all tested elements, with the greatest reductions for $\mathrm{Pb}, \mathrm{Zn}, \mathrm{Cd}$, and Co (Exhibit 8). For example, the addition of 10\% NCA to the sediment resulted in about a 40\% reduction in the PMF values for Co, Cd, Pb, and Zn (Exhibit 8). Of all tested elements, As had the highest RF value in the untreated sediment: 84 \% (Exhibit 8). When the mobile fraction is very limited, like As, the addition of amendments reduces the PMF and increases the RF less substantially (Exhibit 8).

\section{Evaluation of Diffusive Transport through Active Caps}

\section{Effects of Amendments on pH and Electrical Conductivity (EC)}

All cap materials elevated the $\mathrm{pH}$ water in comparison with uncapped sediment, where the initial pH was 4.3 (Exhibit 9). The cap composed of OCB had the highest pH: the initial pH was 11.3 and increased to 12.1 by the end of the experiment. For NAC, XCc, and sand, the pH stabilized after two months and remained fairly constant until the end of the experiment. The pH values in 
these treatments were between 7 and 8 (Exhibit 9). Additionally, materials such as NCA and OCB could cause an increase in $\mathrm{pH}$ of sediment or water due to the high alkalinity of these materials.

Changes in $\mathrm{pH}$ resulting from the application of amendments can be important because of the potential effects of $\mathrm{pH}$ on aquatic organisms. Most freshwater lakes, streams, and ponds have a natural $\mathrm{pH}$ in the range of 6 to 8, and extreme $\mathrm{pH}$ can harm invertebrates and fish. When the pH of freshwater becomes highly alkaline (e.g., 9.6), the effects on fish may include death, damage to outer surfaces like gills, eyes, and skin, and an inability to dispose of metabolic wastes. High pH may also increase the toxicity of other substances. For example, the toxicity of ammonia is ten times more severe at $\mathrm{pH} 8$ than at $\mathrm{pH}$ 7, and the mobility of potentially toxic metals including As, Mo, Se, and Cr increases with $\mathrm{pH}$. Harmful effects can also occur when the $\mathrm{pH}$ falls below 6 and especially below 5. As the $\mathrm{pH}$ approaches 5, non-desirable species of plankton may begin to predominate in some aquatic systems and populations of desirable fish may diminish. Calcium levels in female fish may decline to the point that egg production fails or eggs and/or larvae develop abnormally. Acidity can also result in the release of aluminum ions $\left(\mathrm{Al}^{3+}\right)$ attached to minerals in nearby sediment, resulting in excessive mucus formation by fish that can cause asphyxiation by clogging their gills. Therefore, it is important to carefully monitor the effects of potential active cap materials on $\mathrm{pH}$. Identification of amendments or combinations of amendments that avoid large and/or rapid changes in $\mathrm{pH}$ may be an important factor in the development of an active capping system that results in minimal environmental impact.

Electrical conductivity (EC) decreased for almost all amendments after six months (Exhibit 10). The highest shift in EC values were observed for OCB (Exhibit 10). 
Also, the aqueous TOC concentration was elevated in the experimental columns containing caps with the biopolymer XCc, and OCB by the end of the six month diffusion experiment (Exhibit 11). Elevated aqueous TOC in the columns with biopolymer caps may reflect the release of carbon from the biopolymers.

\section{Diffusion of metals through active caps}

Diffusion is a spontaneous process that results in the movement of a solute. It is caused by the random thermal motion of a solute in solution and is driven by concentration gradients. Solutes move from areas of high concentration to areas of low concentration. The release of all tested metals (Cd, $\mathrm{Cr}, \mathrm{Co}, \mathrm{Cu}, \mathrm{As}, \mathrm{Ni}, \mathrm{Se}$, and $\mathrm{Pb}$ ) by diffusion from uncapped sediment (i.e., the control treatment) was observed after 48 hours, and concentrations in the water column remained relatively high during the rest of the experiment (Exhibit 12). In contrast, metal concentrations in the water column were substantially lower in all columns in which the sediment was capped (Exhibit 12).

ANOVA indicated significant $(\mathrm{P} \leq 0.05)$ differences among treatments for all metals as a result of higher metal concentrations in the columns with uncapped sediment (the only exception was $\mathrm{Pb}$, which did not meet the requirements for testing because of the prevalence of zeros in the data). It also showed significant changes in metal concentrations over time and, for most metals, a significant interaction among treatment and time indicating that changes in metal concentrations over time differed among treatments. A typical example is Cd, which was present in significantly higher concentrations in the control columns with uncapped sediment than in the columns with capped sediment (Exhibit 13). In addition, Cd concentrations tended to decrease over time in the columns with capped sediment but remained relatively constant in the control columns with uncapped sediment. 
As was expected, all cap materials prevented desorption of metals from the underlying sediment over the six month period represented by the study. These data are in agreement with model predictions, which show that even sand will retain metals in sediment for one year in the absence of transport mechanisms other than diffusion (Knox et al., 2011; Dixon and Knox, 2012). Over longer periods, the metal binding capacity of active sequestering agents becomes critical, and it significantly retards the release of sediment contaminants compared with inert materials such as sand (Knox et al., 2012; Dixon and Knox, 2012).

\section{Zone of Influence (ZOI) of active caps}

All cores were separated into cap material and four sediment layers at the end of the diffusion experiment to evaluate the effects of cap materials on sediment chemistry and the vertical distribution of metals in the sediment profile beneath the caps. In the presence of an apatite cap, water extractable $\mathrm{Pb}$ concentrations in all four layers of the sediment were substantially lower than in the corresponding layers from the control treatment (i.e., uncapped sediment) and sand cap treatment (Exhibit 14). The concentrations of other metals such as Cd, Co, Cr, and Zn were also lower, especially in the first $2.5 \mathrm{~cm}$ of sediment beneath the caps with NCA, OCB, and biopolymer/NCA/OCB (Exhibit 15). The sand cap did not affect the vertical distribution of metals in the sediment profile; metal concentrations in water extracts from the sediment below the sand cap remained the same as in the sediment without a cap; therefore, the results for untreated sediment are not shown in Exhibits 14 and 15.

\section{CONCLUSIONS}

This paper identified and evaluated useful active cap materials and the effects of these materials on metal bioavailability and retention under laboratory conditions. Sequestering agents including apatite, organoclay, biopolymers, and zeolite individually and in mixtures have high potential for 
the design of an environmentally benign, active cap that is effective for the remediation of inorganic contaminants in water and sediments. Active caps composed of these materials can alter metal chemistry to increase the proportion of metal species that are relatively immobile and less bioavailable, thereby reducing the likelihood that metal contaminants will migrate from the sediments into aquatic food chains. An additional potential benefit of caps composed of active amendments is the creation of a zone-of-influence beneath the caps in which metal mobility is reduced as a result of in situ changes in metal speciation. This effect further reduces the risk posed by contaminated sediment in the case when the integrity of the active cap is broached by bioturbating organisms or other physical disturbances.

\section{ACKNOWLEDGMENTS}

This work was sponsored by the DoD Strategic Environmental Research and Development Program (SERDP) under project ER 1501 and the Savannah River National Laboratory (SRNL) Mini-Sabbatical Program. The SRNL is operated by Savannah River Nuclear Solutions, LLC for

the U.S. Department of Energy under Contract DE-AC09-798861048. The authors would like to thank to Dr. D. D. Reible (University of Texas, TX) and Dr. N. S. Fisher (Stony Brook University, NY) for providing the sediment samples.

\section{REFERENCES}

Alther, G. (2002). Organoclays remove organics and metals from water. In P.T. Kostecki, E.J. Calabrese, and J. Dragun (Eds.), Contaminated Soils, Vol.7, (pp. 223-231). Amherst, MA: Amherst Scientific Publishers.

Chen, X.B., Wright, J.V., Conca, J.L., and Peurrung L.M. (1997). Effect of pH on heavy metals sorption on mineral apatite. Environmental Science and Technology, 31, 624-631. 
Dixon, K.L. and Knox, A.S. (2012). Sequestration of metals in active cap materials: A laboratory and numerical evaluation. Remediation: The Journal of Environmental Cleanup Costs, Technologies, \& Techniques, 22(2):81-91.

Dudley, L.M., McLean, J.E., Sims, R.C., and Jurinak, J.J. (1991). Sorption of Cd and Cu from acid mine waste extract by two calcareous soils: Column studies. Soil Science, 151,121-135.

Griscom, S.B., Fisher, N.S., and Luoma, S.N. (2000). Geochemical influences on assimilation of sediment-bound metals in clams and mussels. Environmental Science and Technology, 34, 91-99.

Knox A. S., Kaplan, D. I., \& Paller, M. H. (2006 a). Phosphate sources and their suitability for remediation of contaminated soils. Science of the Total Environment, 357, 271-279.

Knox, A.S., Paller, M., Nelson, E., Specht, W., and Gladden, J. (2006 b). Contaminant assessment and their distribution and stability in constructed wetland sediments. Journal of Environmental Quality, 35, 1948-1959.

Knox, A.S., Paller, M.H, Dixon, K.L., Reible, D.D., Roberts, J., and Petrisor, I.G. (2011). Innovative in-situ remediation of contaminated sediments for simultaneous control of contamination and erosion. Final Report PART I, 2011 SRNL-RP-2010-00480.

Knox, A.S., Paller, M.H., and Roberts, J. (2012). Active capping technology - new approaches for in situ remediation of contaminated sediments. Remediation: The Journal of Environmental Cleanup Costs, Technologies, \& Techniques, 22(2):93-117.

Lagaly, G. (1984). Clay-Organic complexes and interactions. Phil. Trans. R. Soc. London, A311, pp. 315-332. 
Lee, B.G., Griscom, S.B., Lee, J.S., Choi, H.J., Koh, C.H., Luoma, S.N., and Fisher, N.S. (2000). Influences of dietary uptake and reactive sulfide on metal bioavailability from aquatic sediments. Science, 287, 282-284.

Ma, L.Q. and Rao, G.N. (1997). The effect of phosphate rock on Pb distribution in contaminated soils. Journal of Environmental Quality, 26, 259-264.

McLean, J.E. and Bledsoe, B.E. (1992). Ground water issue: Behavior of metals in soil. EPA/540/S-92/018 (archived at URL: www.epa.gov/swertio1/tsp/download/issue14.pdf).

Ruby, M.V., Davis, A., Schoof, R. Eberle, S., and Sellstone, C.M. (1996). Estimation of lead and arsenic bioavilability using a physiologically base extraction test. Environmental Science and Technology, 30, 422-430.

Schmuhl, R., Krieg, H.M., Keizer, K. (2001). Adsorption of Cu(II) and Cr(VI) ions by chitosan: Kinetics and equilibrium studies. Water SA, 27(1), 1-7.

Simpson, S.L., Pryor, I. D., Pryor, Mewburn, B. R., Batley, G. E., and Jolley, D. (2002). Considerations for capping metal-contaminated sediments in dynamic estuarine environments. Environmental Science and Technology, 36: 3772-3778.

Soundarajan, R., Barth, E.F., and Gibbons, J.J. (1990). Using an organophilic clay to chemically stabilize waste containing organic compounds. Hazardous Material Control, 3(1), 42-45.

Tessier, A., Campbell, P.G.C., and Bisson, M. (1979). Sequential extraction procedure for the speciation of particulate trace metals. Analytical Chemistry, 51, 844-850.

Vankar, P.S. and Tiwari, V. (2001). Toxic metal removal by using Cyclodextrins, AnalyticalScience.com, BioAnalytical and BioAssays, 2001_BA006.

Wright, J.V., Peurrung, L.M., Moody, T.E., Conca, J.L., Chen, X., Didzerekis, P.P., Wyse, E. (1995). In Situ Immobilization of Heavy Metals: Apatite Mineral Formations. Technical 
Report to the Strategic Environmental Research and Development Program, Department of Defense, Pacific Northwest National Laboratory, Richland; 154pp.

Xu, S., Sheng, G., \& Boyd, S.A. (1997). Use of organoclays in pollutant abatement. Advances in Agronomy, 59, 25-62.

Yong, R.N. (2001). Geoenvironmental Engineering: Contaminated Soils, Pollutant Fate and Mitigation. CRC Press, Boca Raton, FL.

Zhang, H. and Davison, W. (1995). Performance characteristic of the technique of diffusion gradients in thin-films (DGT) for the measurement of trace metals in aqueous solution. Analytical Chemistry, 67, 3391-3400. 
Exhibit 1. Sequential extraction procedure employed for the geochemical fractionation of the untreated sediments and sediments treated with amendments.

\begin{tabular}{|l|l|l|l|}
\hline Step & $\begin{array}{l}\text { Operationally } \\
\text { defined fraction }\end{array}$ & Reagents & $\begin{array}{l}\text { Extraction } \\
\text { time }\end{array}$ \\
\hline 1 & exchangeable & $1.0 \mathrm{M} \mathrm{MgCl}_{2}$ & $1 \mathrm{~h}$ \\
2 & carbonates & $1.0 \mathrm{M} \mathrm{CH}_{3} \mathrm{COOHNa}$ & $6 \mathrm{~h}$ \\
3 & amorphous oxides & $0.25 \mathrm{M} \mathrm{NH}_{2} \mathrm{OH} \cdot \mathrm{HCl}$ in $0.25 \mathrm{M} \mathrm{HCl}$ & $2 \mathrm{~h}$ \\
4 & crystalline oxides & $1.0 \mathrm{M} \mathrm{NH}_{2} \mathrm{OH} \cdot \mathrm{HCl}$ in $25 \% \mathrm{CH}_{3} \mathrm{COOH}$ & $3 \mathrm{~h}$ \\
5 & organic & $0.1 \mathrm{M} \mathrm{Na}_{4} \mathrm{P}_{2} \mathrm{O}_{7}$ & $24 \mathrm{~h}$ \\
6 & sulfide & $4.0 \mathrm{~N} \mathrm{HNO}_{3}$ & $30 \mathrm{~min}$ \\
7 & residual & $\mathrm{HNO}_{3} / \mathrm{HCl}$ (agua reqia) & \\
\hline
\end{tabular}



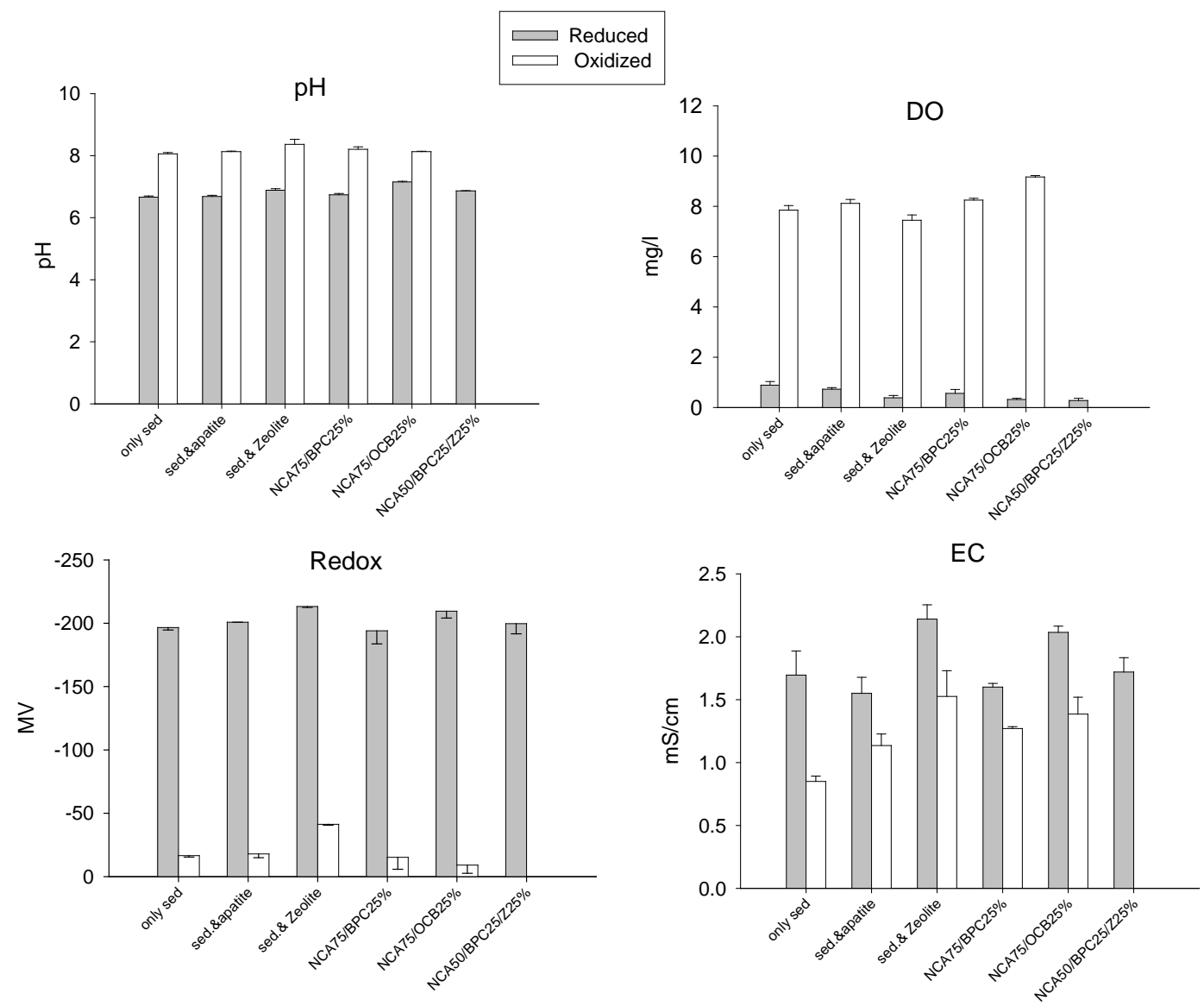

Exhibit 2. Effect of amendments on Anacostia River sediment properties under oxidized and reduced conditions; NCA = North Carolina apatite, $\mathrm{OCB}=$ organoclay 750 from Biomin, Inc., BPC = chitosan biopolymer, $\mathrm{Z}=$ zeolite. 
Exhibit 3. Effect of amendments on $\mathrm{Ca}, \mathrm{Fe}, \mathrm{Mn}$, and $\mathrm{P}$ concentrations $\left(\mathrm{mg} \mathrm{L}^{-1}\right)$ in water extracts from reduced and oxidized treatments of the Anacostia River sediment.

\begin{tabular}{|llllllllll|}
\hline \multirow{3}{*}{ Treatments } & \multicolumn{3}{c}{ Reduced } & \multicolumn{7}{c|}{ Oxidized } \\
\hline & & Ca & Fe & Mn & P & Ca & Fe & Mn & P \\
\hline Ctrl & Avg & 310.8 & 88.3 & 12.0 & 2.5 & 126 & 0.37 & 3.39 & 0.76 \\
NCA & Avg & 265.5 & 68.0 & 8.6 & 3.3 & 215.4 & 0.39 & 4.83 & 1.40 \\
ZC & Avg & 137.8 & 36.8 & 5.4 & 2.5 & 61.4 & 0.71 & 1.81 & 0.80 \\
NCA/BPC & Avg & 236.9 & 48.8 & 6.8 & 1.5 & 181.3 & 0.22 & 4.24 & 0.80 \\
NCA/OCB & Avg & 385.9 & 8.2 & 2.6 & 2.0 & 225.7 & 0.29 & 2.56 & 1.56 \\
NCA/BPC/Z & Avg & 195.5 & 39.3 & 5.8 & 1.6 & 111.3 & 0.19 & 3.33 & 0.52 \\
Ctrl & Stdev & 8.3 & 3.0 & 0.2 & 0.1 & 22.1 & 0.05 & 0.29 & 0.11 \\
NCA & Stdev & 30.6 & 5.8 & 1.1 & 0.1 & 47.5 & 0.27 & 1.81 & 0.35 \\
ZC & Stdev & 3.0 & 0.6 & 0.1 & 0.1 & 17.7 & 0.30 & 0.54 & 0.68 \\
NCA/BPC & Stdev & 8.6 & 5.0 & 0.4 & 0.1 & 28.8 & 0.03 & 0.25 & 0.04 \\
NCA/OCB & Stdev & 50.6 & 0.8 & 0.1 & 0.2 & 7.7 & 0.01 & 0.10 & 0.74 \\
NCA/BPC/Z & Stdev & 8.5 & 0.6 & 0.2 & 0.2 & 89.4 & 0.08 & 4.42 & 0.09 \\
\hline
\end{tabular}


Exhibit 4. Comparison of element concentrations $\left(\mu \mathrm{g} \mathrm{L}^{-1}\right)$ in water extracts from the Anacostia River sediment under reduced and oxidized conditions.

\begin{tabular}{|ccccc|}
\hline Elements & \multicolumn{2}{c}{ Reduced } & \multicolumn{2}{c|}{ Oxidized } \\
& Avg & Stdev & Avg & Stdev \\
\hline $\mathrm{Cr}$ & 77.0 & 5.2 & 28.4 & 1.4 \\
$\mathrm{Co}$ & 16.9 & 1.2 & 3.6 & 0.2 \\
$\mathrm{Ni}$ & 56.9 & 0.9 & 11.3 & 0.6 \\
$\mathrm{Cu}$ & 33.1 & 15.5 & 25.7 & 0.4 \\
$\mathrm{Zn}$ & 137.5 & 10.6 & 85.1 & 6.5 \\
$\mathrm{As}$ & 23.1 & 2.8 & 3.3 & 0.2 \\
$\mathrm{Se}$ & 7.1 & 0.2 & 2.0 & 0.1 \\
$\mathrm{Cd}$ & 0.40 & 0.08 & 0.12 & 0.05 \\
$\mathrm{~Pb}$ & 22.8 & 0.4 & 4.6 & 0.4 \\
$\mathrm{Ca}$ & 310.8 & 8.3 & 126.0 & 8.3 \\
$\mathrm{Fe}$ & 88.3 & 3.0 & 0.4 & 0.1 \\
$\mathrm{Mn}$ & 12.0 & 0.2 & 3.4 & 0.3 \\
$\mathrm{P}$ & 2.5 & 0.1 & 0.8 & 0.1 \\
\hline
\end{tabular}



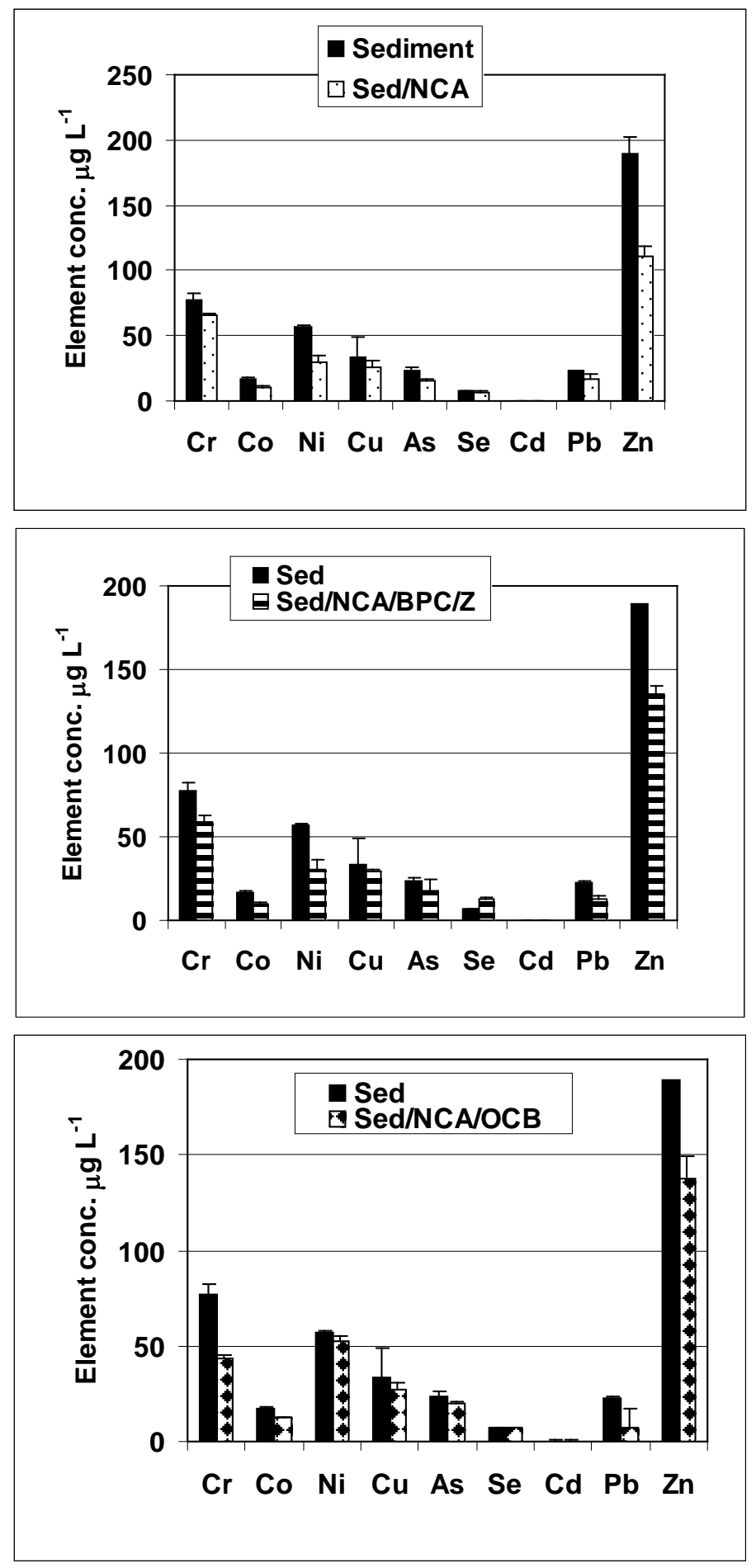

Exhibit 5. Effect of amendments on metal concentrations in water extracted from Anacostia River sediment after eight weeks of contact with amendments ( $2 \%$ dry weight) under reduced conditions $(\sim-200 \mathrm{mV})$. 

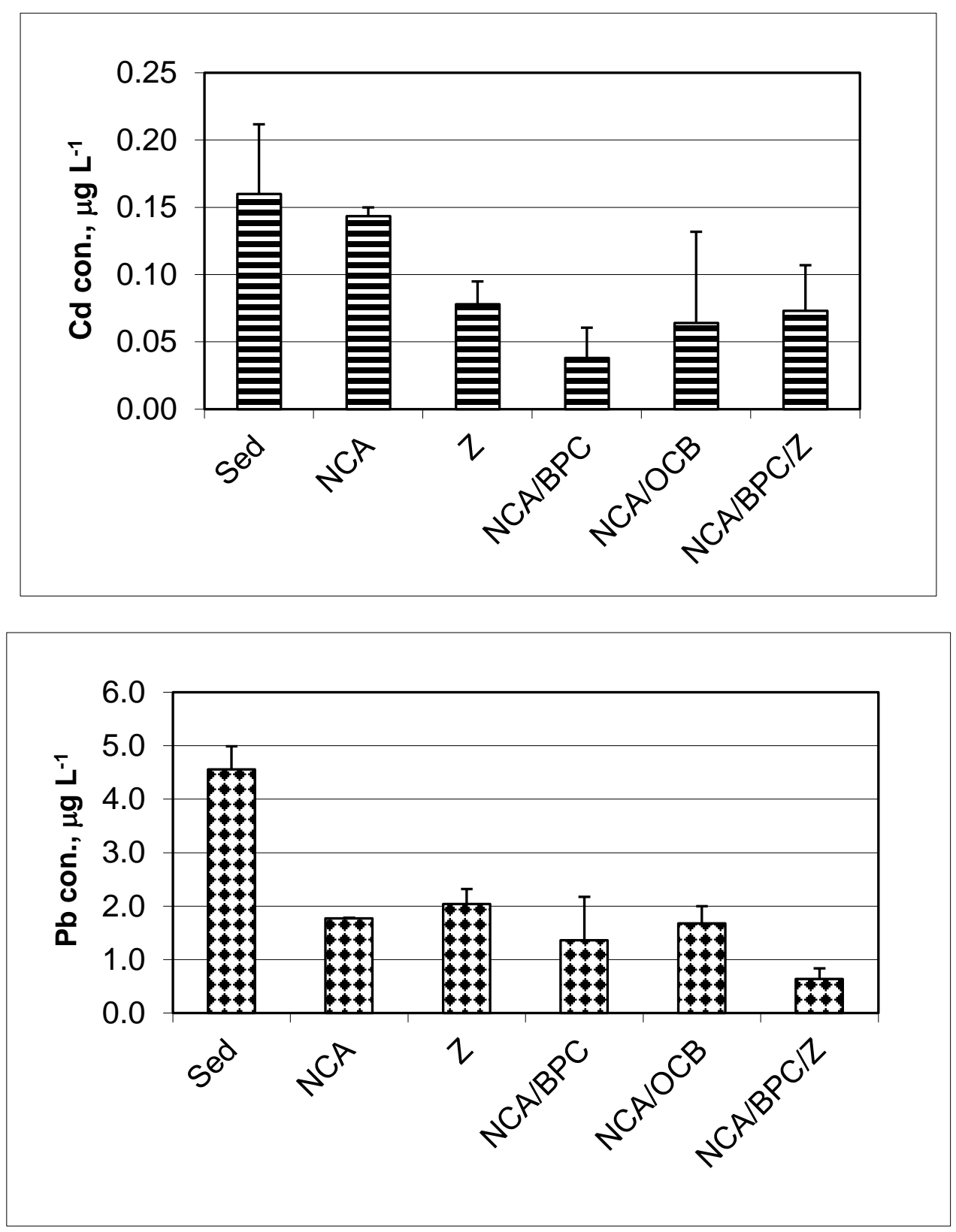

Exhibit 6. Effect of amendments on metal concentrations in water extracted from Anacostia sediment after eight weeks of contact with amendments (2\% dry weight) under oxidized conditions. 

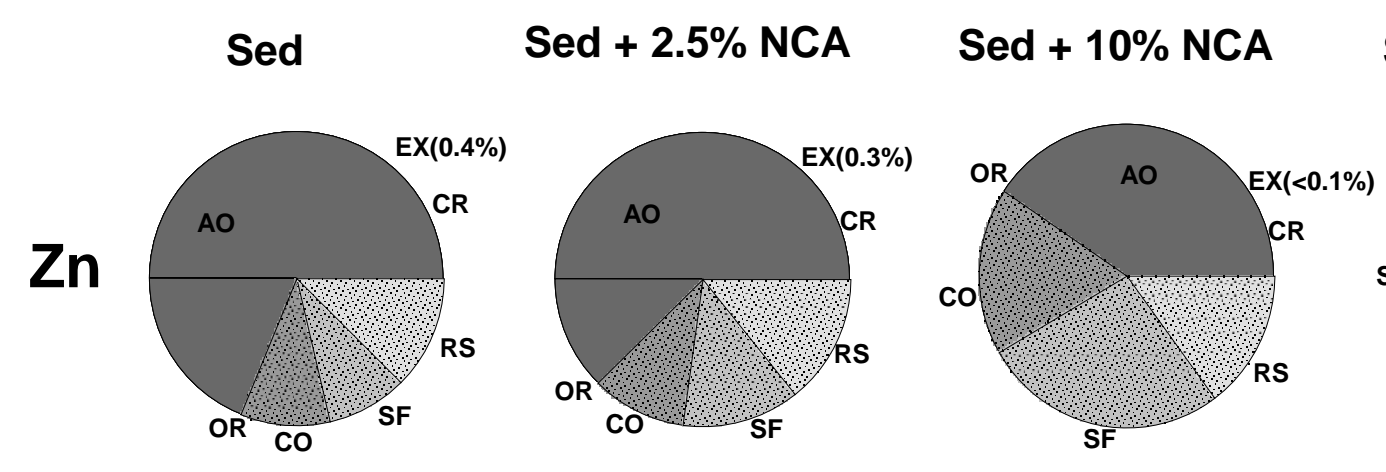

Sed $+2.5 \%$ OCB
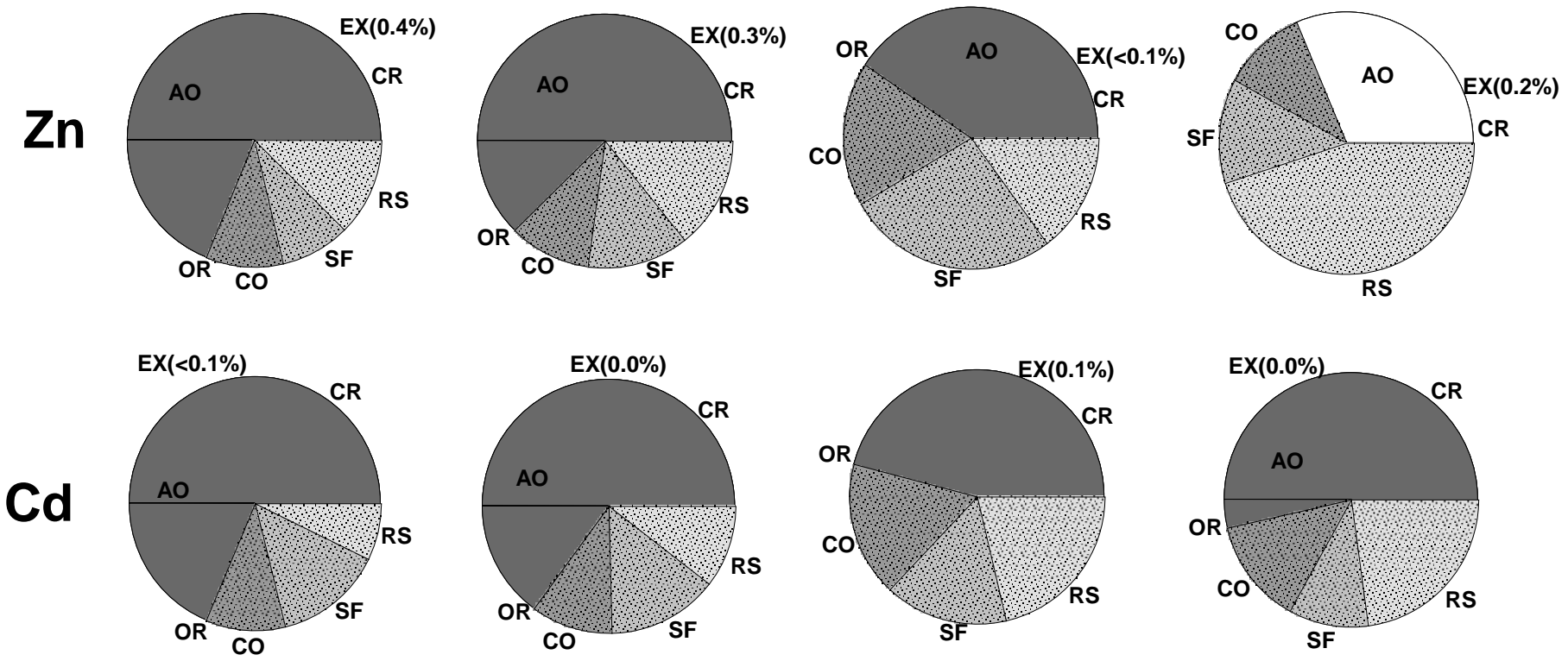

RS
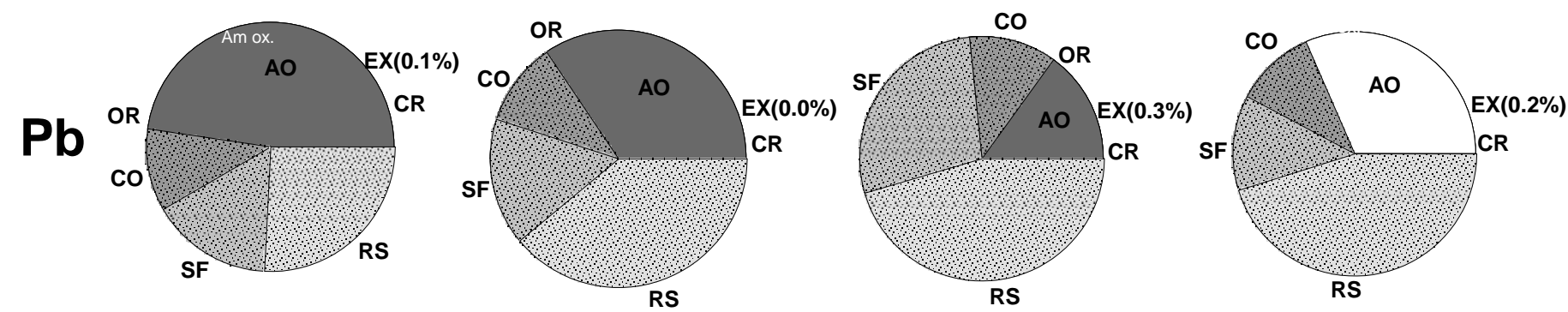

Exhibit 7. Effect of apatite (NCA) and organoclay (OCB750) amendments (2.5and 10\% dry weight) on the partitioning of Cd, Pb, and $\mathrm{Zn}$ in Elizabeth River Sediment (Sed); EX. = exchangeable fraction, $\mathrm{CR}=$ carbonate fraction, $\mathrm{AO}=$ amorphous fraction, $\mathrm{CR}=$ crystalline oxide, $\mathrm{OR}$ = organic, $\mathrm{SF}$ = sulfide, and RS = residual. Confetti pattern indicates the recalcitrant factor; i.e., the metal fractions that are largely immobile and less bioavailable. 

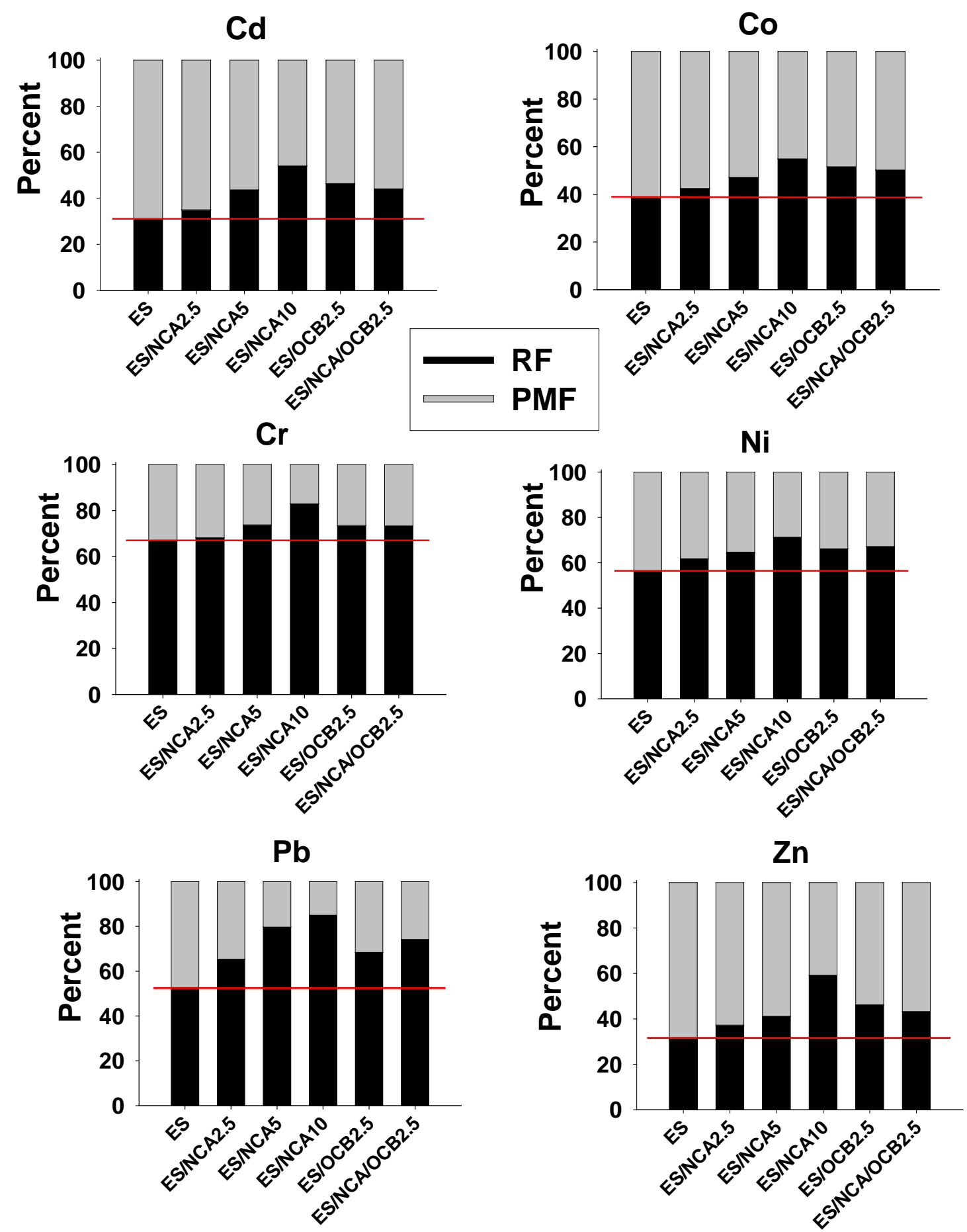

Exhibit 8. Average potentially mobile fraction (PMF) and recalcitrant factor (RF) for Cd, $\mathrm{Co}, \mathrm{Cr}, \mathrm{Ni}, \mathrm{Pb}$, and $\mathrm{Zn}$ in the untreated and treated Elizabeth River sediment (ES). The horizontal line represents the partitioning of untreated sediment. Amendment doses were $2.5,5$, and $10 \%$ dry weight. 


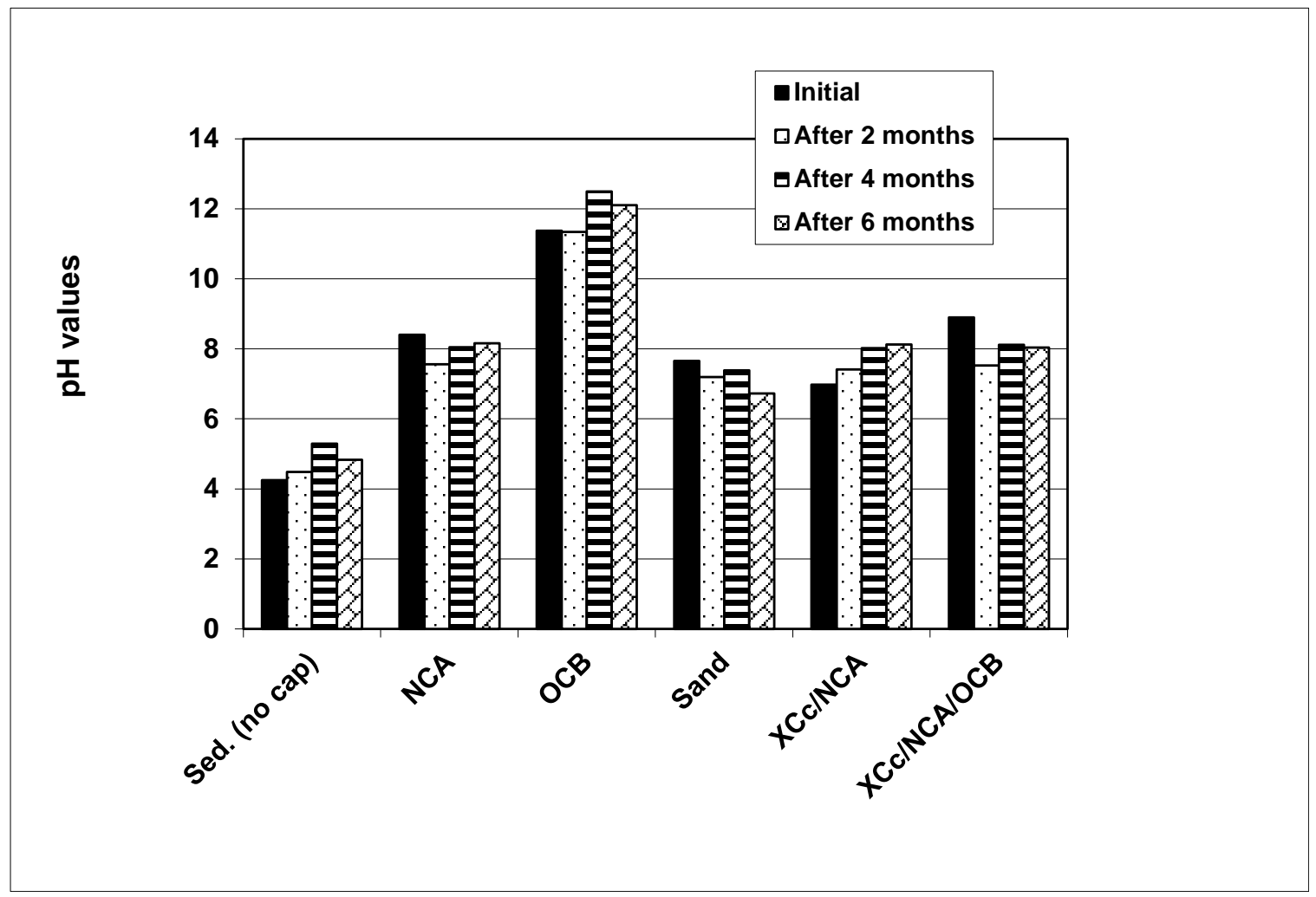

Exhibit 9. Changes in $\mathrm{pH}$ with time in the diffusion experiment. 


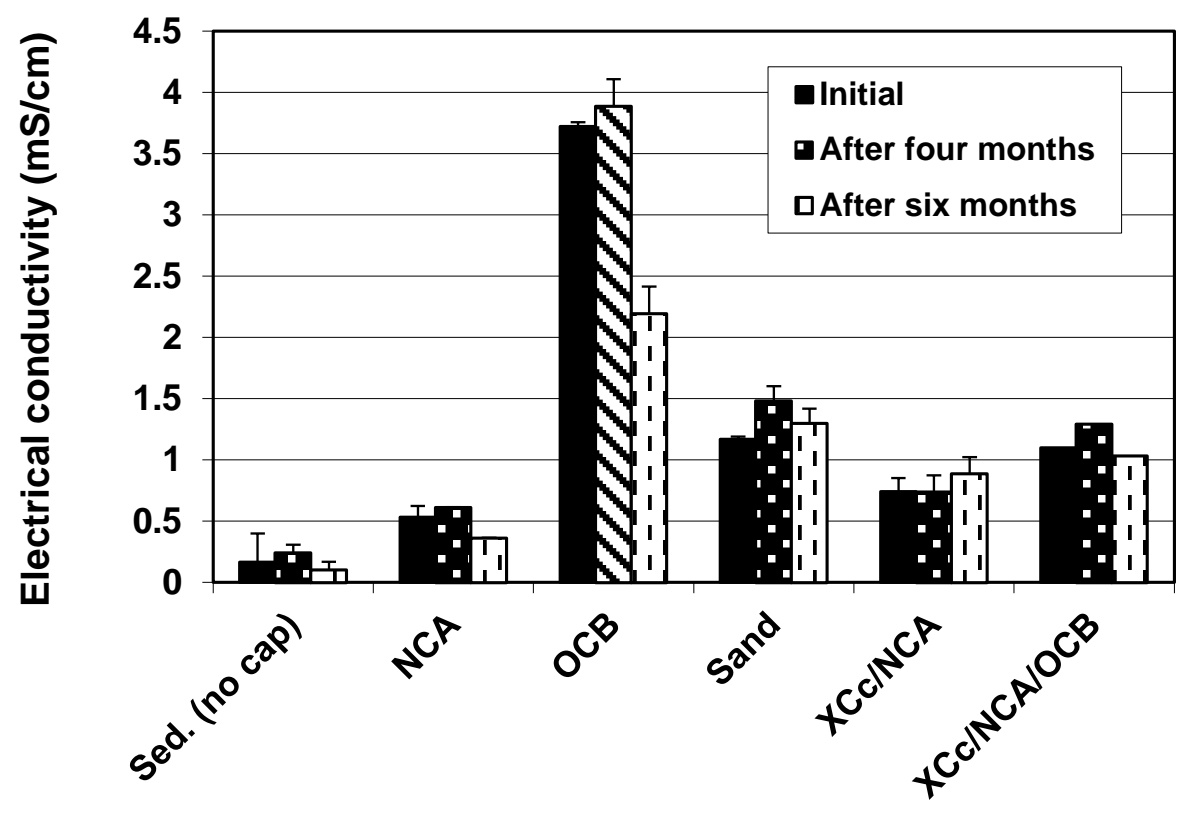

Exhibit 10. Electrical conductivity in the diffusion experiment. 

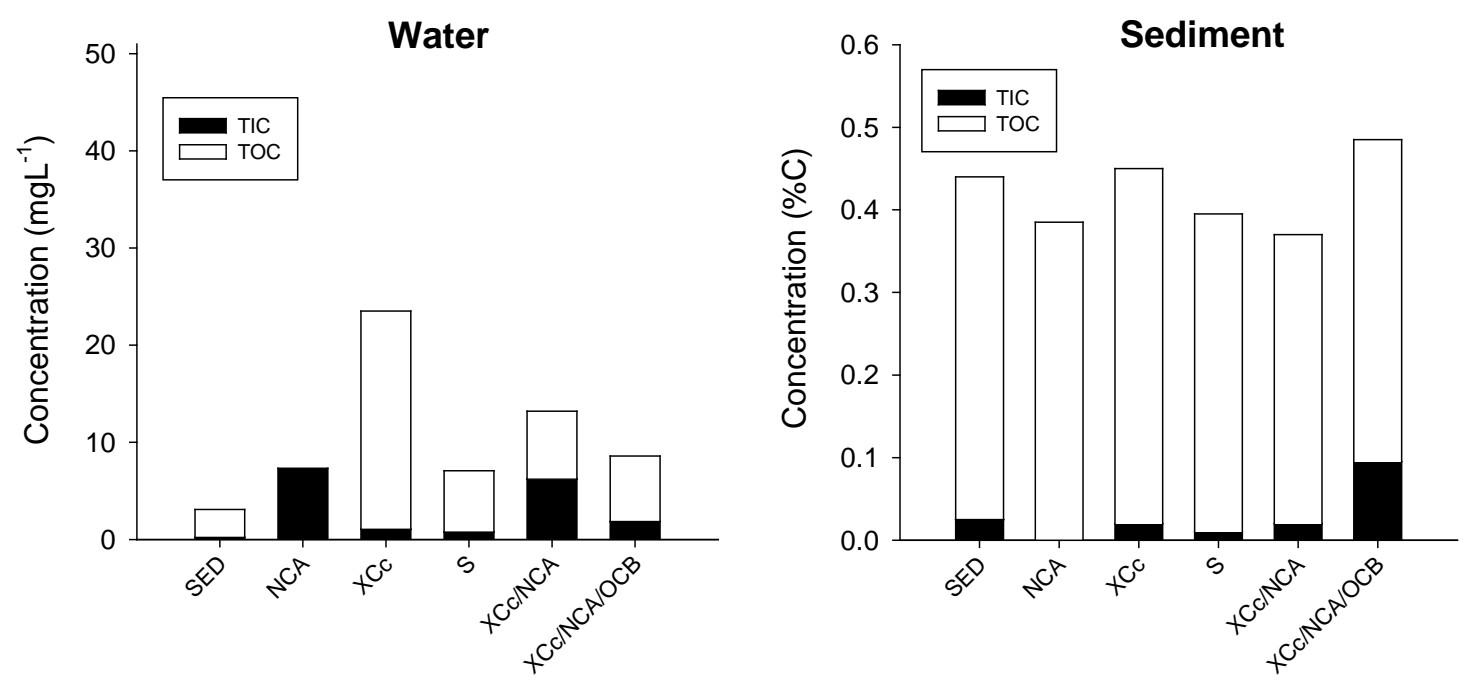

Exhibit 11. Total inorganic (TIC) and total organic (TOC) carbon in water and sediment after the six month diffusion experiment. 

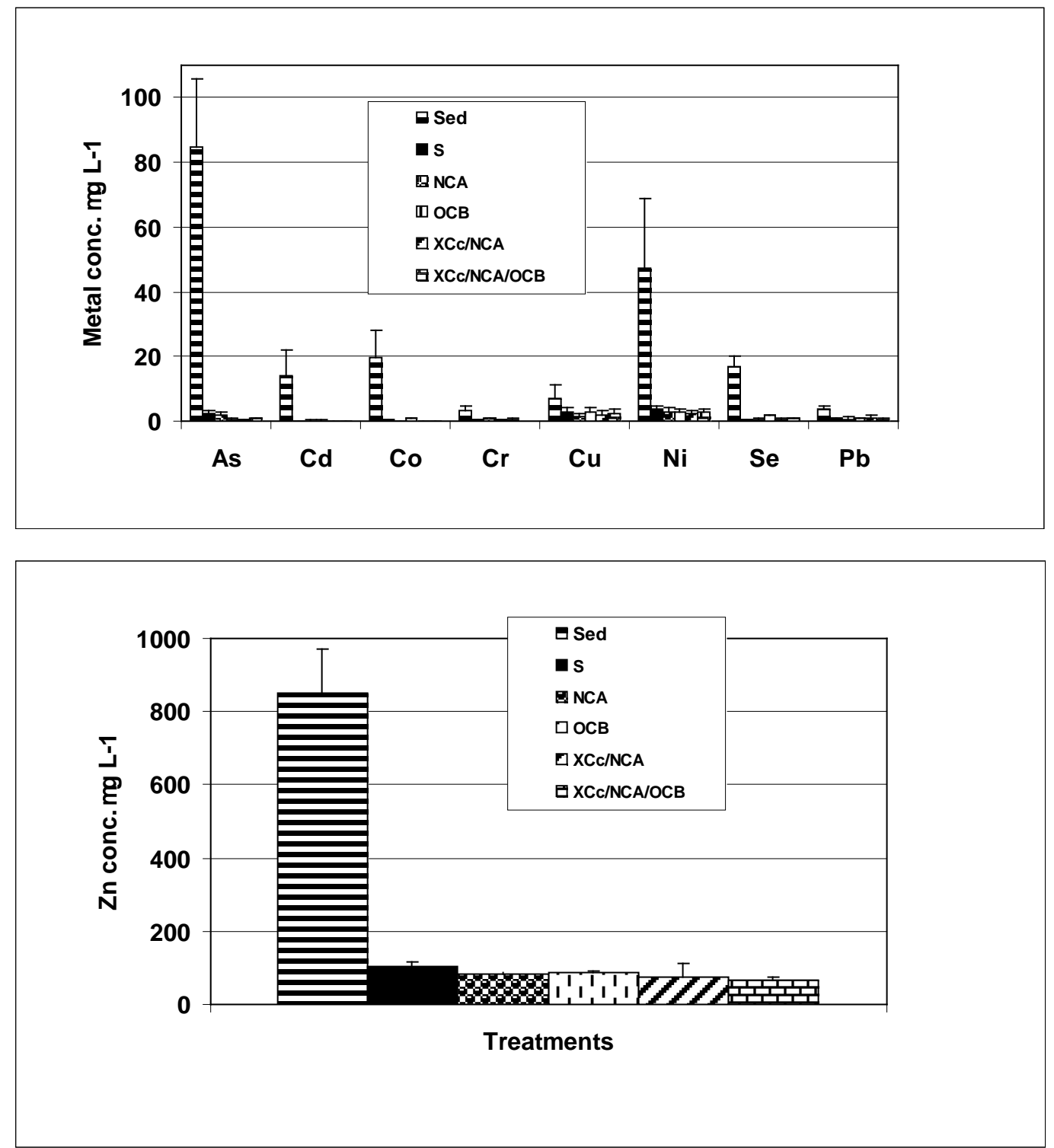

Exhibit 12. Average metal releases in diffusion experiment after six months. 


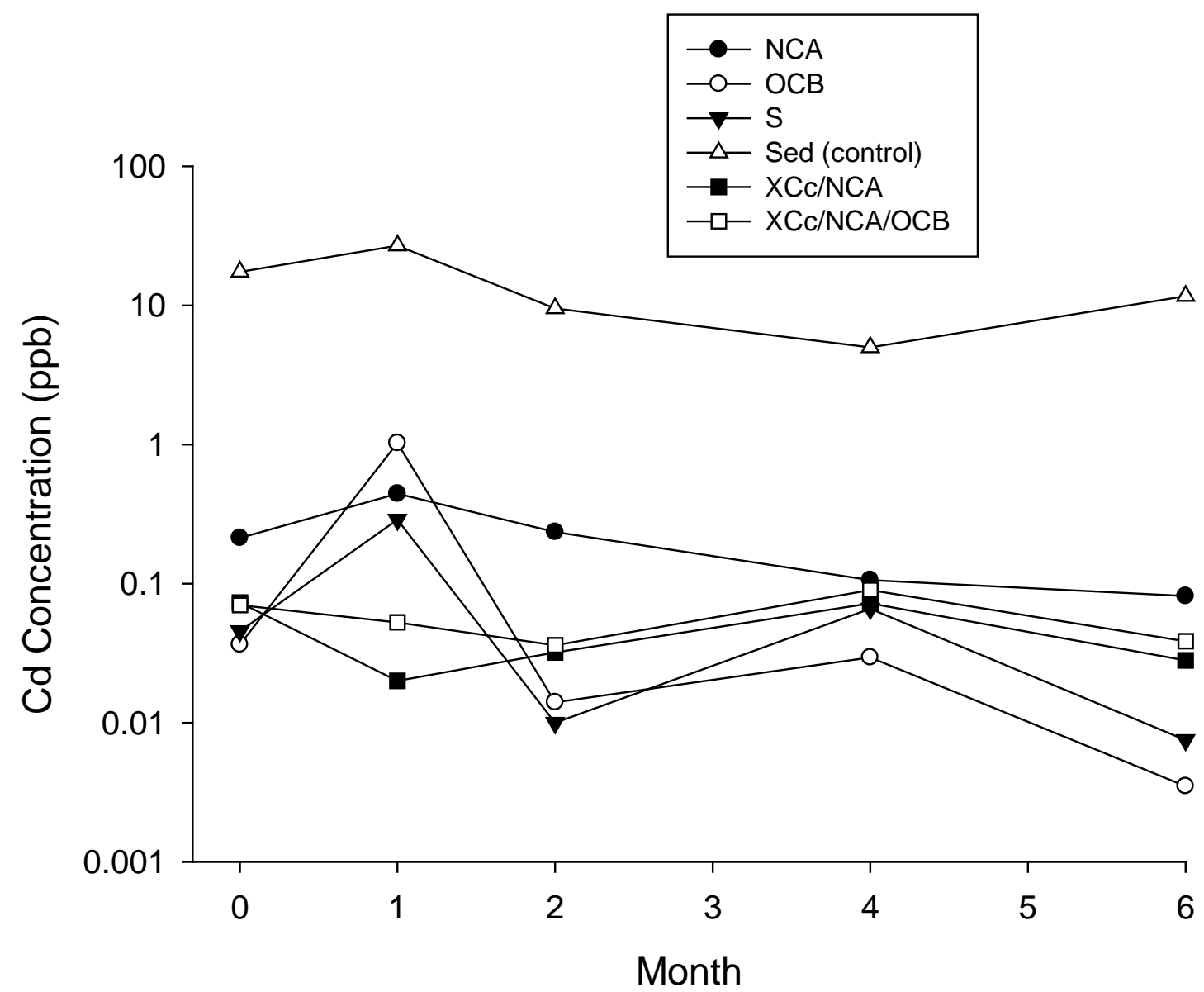

Exhibit 13. Changes in cadmium concentrations over time in the diffusion experiment. 


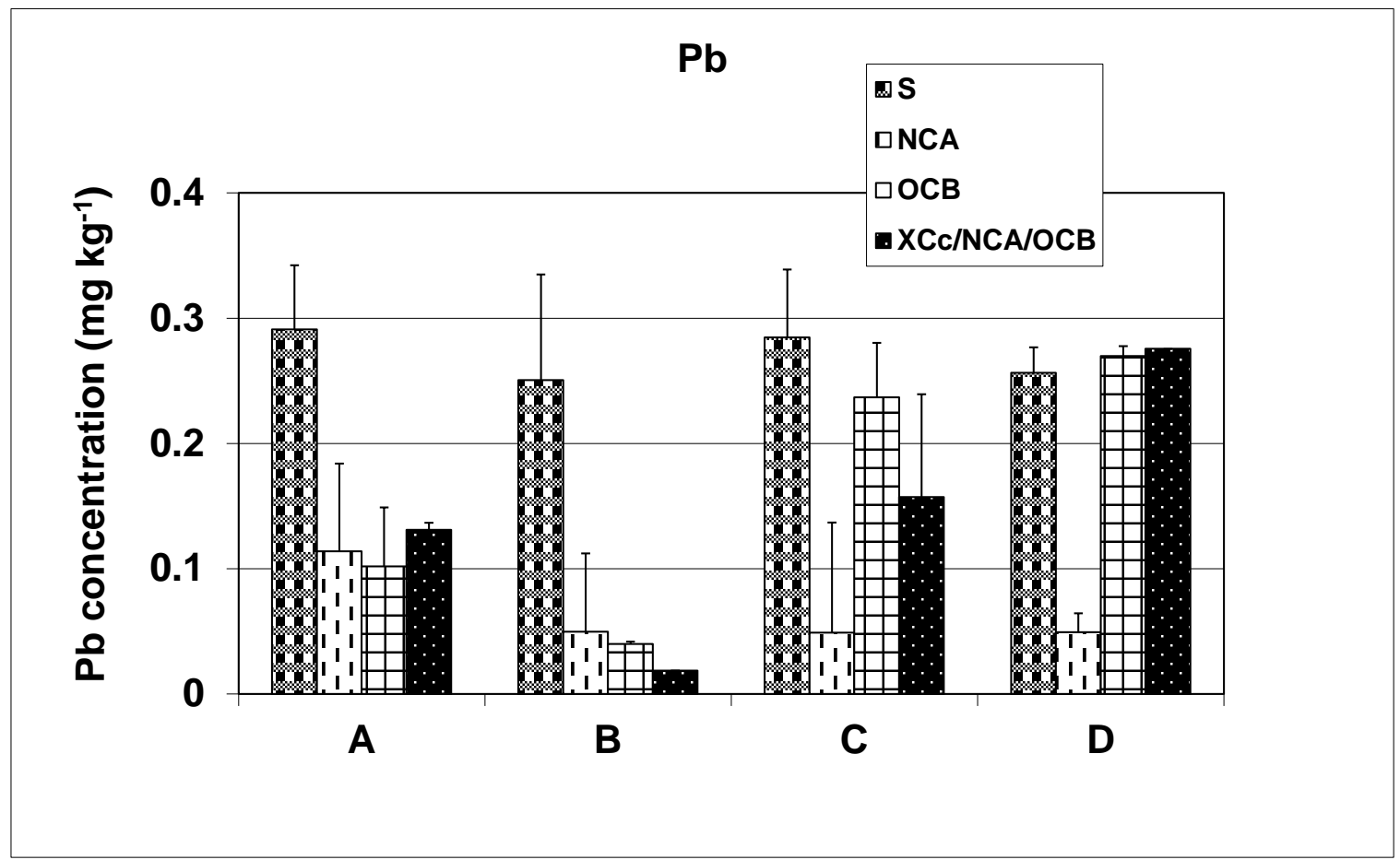

Exhibit 14. Lead concentrations in water extracts from four sediment layers $(A=0-1.5$ $\mathrm{cm}, \mathrm{B}=1.5-2.5 \mathrm{~cm}, \mathrm{C}=2.5-5 \mathrm{~cm}$, and $\mathrm{D}=5-10 \mathrm{~cm}$ ) collected from below each type of cap: (sand [S]; apatite [NCA]; organoclay [OCB]; and a mixture of apatite, organoclay, and biopolymer [XCc/NCA/OCB]). 


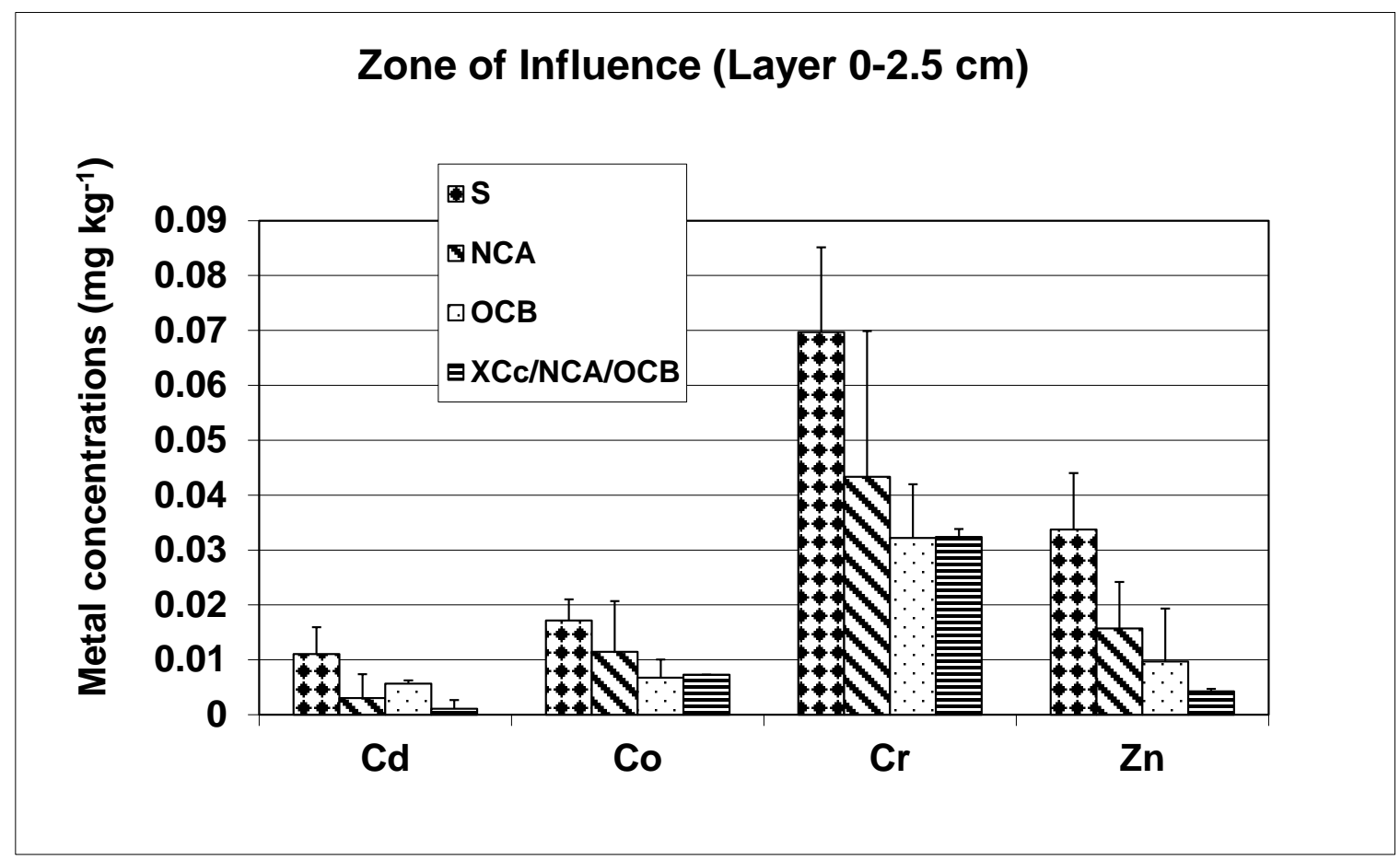

Exhibit 15. Metal concentrations in water extracts from sediment collected from below each type of cap (sand [S]; apatite [NCA]; organoclay [OCB]; and a mixture of apatite, organoclay, and biopolymer [XCc/NCA/OCB]). 